\title{
UTILIZAÇÃO DE MARCADORES ISSR NA AVALIAÇÃO DA DIVERGÊNCIA GENÉTICA ENTRE ACESSOS DE BIRIBAZEIRO ${ }^{1}$
}

\author{
RODRIGO MONTE LORENZONI², TAÍS CRISTINA BASTOS SOARES ${ }^{3}$, \\ VERÔNICA FEIJOLI SANTIAGO ${ }^{4}$, JOSIMAR ALEIXO DA SILVA ${ }^{5}$, RUIMÁRIO INÁCIO COELHO ${ }^{6}$
}

RESUMO-O biribazeiro é uma planta frutífera nativa das matas Atlântica e Amazônica. Seus frutos têm grande aceitação popular para consumo in natura. Objetivou-se com este estudo a avaliação da diversidade genética de acessos de biribazeiro (Rollinia mucosa [Jacq.] Baill) com a utilização de marcadores moleculares ISSR. Foram analisados 16 acessos com 20 primers ISSR, os quais produziram um total de 118 bandas, sendo 96 polimórficas e 22 monomórficas. Os valores de dissimilaridade genética, calculados de acordo com o complemento do índice de Jaccard, variaram de 0,0909 a 0,5147. O método UPGMA (Unweighted Pair Group Method Average) agrupou os acessos em seis grupos. Os acessos 1 e 5 foram mais dissimilares e 11 e 12 os menos dissimilares. Os marcadores ISSR utilizados neste estudo demonstraram eficiência na detecção de polimorfismos moleculares, revelando variabilidade genética entre os 16 acessos. Diante dos resultados obtidos neste trabalho, é possível inferir que existe considerável variabilidade genética entre os acessos de biribazeiro, demonstrando a importância dos marcadores na análise de variabilidade de espécies pouco estudadas, como Rollinia mucosa [Jacq.]Baill.

Termos para indexação: Rollinia mucosa, Annonaceae, variabilidade geética, biribá.

\section{USING ISSR FOR FINGERPRINTING ACCESSIONS OF BIRIBAZEIRO}

\begin{abstract}
The biribazeiro is a fruit plant native from Amazonian and Atlantic forests, in Brazil. Their fruits have great popular acceptance for fresh consumption. The objective of this study was to measure the genetic divergence of biriba genotypes (Rollinia mucosa [Jacq.]Baill) using ISSR molecular markers. Sixteen genotypes of biriba were screened with 20 ISSR primers, which produced a total of 118 bands, with 96 polymorphic and 22 monomorphic fragments. The genetic dissimilarity values ranged from 0.0909 to 0.5147 , based on the complement of the Jaccard index. The UPGMA (Unweighted Pair Group Average Method) grouped the accessions into six groups. The genotypes 1 and 5 were most dissimilar and 11 and 12 the most similar. The ISSR markers used in this study demonstrated the efficiency of molecular polymorphisms detection, revealing high genetic variability among the 16 accessions. So, it can be inferred that there is a considerable genetic variation among accessions of the biribazeiro, showing the importance of molecular markers in the analysis of variability of species poorly studied, as Rollinia mucosa [Jacq.]Baill.

Index terms: Rollinia mucosa, Annonaceae, genetic variability, biribá.
\end{abstract}

\footnotetext{
${ }^{1}$ (Trabalho 116-13) - Recebido em: 14-03-2013. Aceito para publicação em: 12-11- 2013. V Congresso Internacional \& Encontro Brasileiro sobre Annonaceae: do gene à exportação (19 a 23 de Agosto de 2013). Botucatu-SP

${ }^{2}$ Aluno de graduação em Agronomia, UFES, Centro de Ciências Agrárias, Alegre - ES. E-mail: rodrigomlorenzoni@gmail.com ${ }^{3}$ Professora Dra ${ }^{\mathrm{a}}$. na UFES, Centro de Ciências Agrárias, Alegre-ES, tcbsoares@yahoo.com.br

${ }^{4}$ Aluna de graduação em Ciências Biológicas (licenciatura), UFES, Centro de Ciências Agrárias, Alegre - ES, veronicafeijoli_violinista@hotmail.com

${ }^{5}$ Aluno de pós graduação em Produção Vegetal, UFES, Centro de Ciências Agrárias, Alegre - ES, josimaraleixo@hotmail.com ${ }^{6}$ Professor Dr. na UFES, Centro de Ciências Agrárias, Alegre - ES,ruimario.coelho@ufes.br
} 


\section{INTRODUÇÃO}

O biribazeiro (Rollinia mucosa [Jacq.] Baill) é uma planta frutífera nativa das matas Atlântica e Amazônica, pertencente à família Annonaceae, desenvolve-se bem em diferentes habitats e tem o Brasil como centro de origem da diversidade (SANTOS et al., 2005; FERREIRA et al., 2010). De acordo com Costa e Muller (1995), a planta tem ampla dispersão geográfica, e o fruto é conhecido como biribá, biribá- do- Pará, fruta- dacondessa, biribá- de- Pernambuco, anona, pinha ou jaca de pobre. Os frutos têm grande aceitação popular para consumo in natura, sendo a planta ideal para formação de pomares, possibilitando retorno econômico no máximo cinco anos após sua implantação (COSTA; MULLER, 1995; TEIXEIRA; MACEDO, 2011).

No meio científico, o biribazeiro tem sido estudado quanto ao seu uso como porta- enxerto (SANTOS et al., 2005), além de estudos de identificação de suas propriedades medicinais (ESTRADA-REYES et al., 2010) e de resposta nutricional de mudas em função da adubação e da correção do solo (TEIXEIRA; MACEDO, 2011).

Marcadores moleculares são tidos como ferramentas úteis para detecção de variações no genoma, aumentando o poder da análise genética das plantas (CAIXETA et al., 2009). Entre as classes de marcadores moleculares disponíveis, os marcadores ISSR (Inter Simple Sequence Repeats) podem ser utilizados na discriminação e caracterização molecular de indivíduos São regiões genômicas de 100 a 3.000 pb, amplificadas via PCR (Polymerase Chain Reaction)flanqueadas por sequências microssatélites, para as quais são desenhadas primers únicos de 16 a 20 pb ( FALEIRO, 2007).

Os marcadores ISSR têm-se mostrado eficientes em diversos estudos de análise da variabilidade genética em fruteiras, dentre elas a manga (ROCHA et al., 2012) e o umbu-cajazeira (SANTANA et al., 2011). Neste contexto, Dantas et al. (2012) frisam a caracterização molecular como uma importante atividade para o conhecimento no que diz respeito aos germoplasmas. Esse tipo de marcador permite a identificação de ampla variabilidade intra e interespecíficas e, com isso, fundamentam-se como uma ferramenta bastante útil em programas de melhoramento e estudos de diversidade.

O conhecimento da variabilidade genética do biribazeiro é crucial na identificação de genitores para programas de melhoramento genético, para o desenvolvimento de cultivares, inclusive genótipos mais promissores para uso como porta-enxerto. Porém, as informações são escassas, sendo necessários estudos a respeito. $\mathrm{O}$ objetivo deste estudo foi avaliar a divergência genética de 16 acessos de Rollinia mucosa [Jacq.] Baill pertencentes à coleção de trabalho do Centro de Ciências Agrárias da Universidade Federal do Espírito Santo, mediante uso de marcadores moleculares ISSR.

\section{MATERIAL E MÉTODOS}

O experimento foi conduzido no laboratório de Bioquímica e Biologia Molecular do Centro de Ciências Agrárias da Universidade Federal do Espírito Santo, localizado em Alegre - ES (CCAUFES). Foram utilizados 16 acessos de biribazeiro (Rollinia mucosa [Jacq.] Baill) provenientes da coleção de trabalho do CCA-UFES. O acesso 16 foi coletado em Cachoeiro de Itapemirim - ES, e os demais, em Alegre - ES.

Para a extração de DNA, foram utilizadas folhas tenras, completamente desenvolvidas e provenientes do terço médio das plantas, pesando cerca de $200 \mathrm{mg}$ de folhas, para cada amostra. O protocolo adotado para o procedimento de extração foi o proposto por Diniz et al. (2005) modificado, mediante a maceração das folhas em nitrogênio líquido. A quantificação do DNA foi feita a partir da análise comparativa das amostras em gel de agarose a $0,8 \%$, corado por meio de brometo de etídio. Após ser feita a quantificação, as amostras foram diluídas em TE (10 mM Tris- $\mathrm{HCl}$ e 1 mM EDTA em pH 8) e padronizadas em $30 \mathrm{ng} \mu \mathrm{L}^{-1}$.

Foram utilizados um total de 20 primers ISSR. As reações de amplificação foram realizadas em placas para PCR, tendo como volume final $20 \mu \mathrm{L}$ por amostra, contendo: $150 \mathrm{ng}$ de DNA; $0,25 \mu \mathrm{M}$ de cada dNTP; $2 \mathrm{mM}$ de primer; $10 \mathrm{mM}$ Tris- $\mathrm{HCl}(\mathrm{pH}$ 8,5); $50 \mathrm{mM} \mathrm{KCl} ; 2,5 \mathrm{mM}$ de $\mathrm{MgCl}_{2} ; 0,6 \mathrm{U}$ de Taq DNA polimerase. As amplificações foram feitas em termociclador Applied Biosystems, com uma etapa de desnaturação a $94^{\circ} \mathrm{C}$, por $5 \mathrm{~min}$, seguida de 35 ciclos de $94^{\circ} \mathrm{C}$, por $45 \mathrm{~s}$, anelamento de $52^{\circ} \mathrm{C}$, por $45 \mathrm{~s}$, e $72^{\circ} \mathrm{C}$, por $90 \mathrm{~s}$, com extensão final de $72^{\circ} \mathrm{C}$, por $7 \mathrm{~min}$

Os produtos da amplificação foram separados por meio de eletroforese em gel de agarose (Ludwig Biotec $\left.{ }^{\circledR}\right)$ a uma concentração de $2,5 \%$, numa voltagem de 100 Volts, por 4 horas. Após a separação dos fragmentos, os produtos da amplificação foram corados com brometo de etídio na concentração de $0,25 \mu \mathrm{g} / \mathrm{mL}$ e, em seguida, expostos à luz ultravioleta e fotografados. Os produtos amplificados foram 
avaliados como presença (1) ou ausência (0) de bandas. A distância genética entre os indivíduos foi baseada na dissimilaridade genética entre os 16 acessos, a qual foi calculada a partir do complemento do coeficiente de Jaccard. Para análise de agrupamento dos acessos pelo método UPGMA (Unweighted Pair Group Method Average), utilizouse dos valores de dissimilaridades genéticas, por meio do software GENES (CRUZ, 2006).

A correlação cofenética foi utilizada para avaliar a consistência dos agrupamentos hierárquicos, pois os dados originais podem gerar certa distorção dos resultados, necessitando de uma adequação (CRUZ; CARNEIRO, 2003).

\section{RESULTADOS E DISCUSSÕES}

Entre os 20 primers testados para averiguar a capacidade de gerar bandas nos acessos de biribazeiro, 13 apresentaram bom padrão de amplificação, bandas nítidas e bem definidas, e estes proporcionaram a obtenção de 118 bandas. A quantidade de bandas por primer variou de 5 (UBC 827) a 13 (UBC 834 e UBC 841) (Tabela1), com média de 9 bandas por primer. Das 118 marcas obtidas, $81,3 \%$ geraram polimorfismo. Esses resultados corroboram os de Santana et al. (2012) que, ao trabalharem com marcadores ISSR em acessos de umbu-cajazeira, encontraram $80 \%$ de polimorfismo, com média de 8 bandas polimórficas por primer. $\mathrm{Na}$ literatura, encontram-se diversos trabalhos utilizando marcadores dominantes (CHEN et al., 2006; CARVALHO et al., 2012), inclusive os ISSR, os quais consideram a porcentagem de locos polimórficos como medida de diversidade genética.

Os valores de dissimilaridade genética (Tabela 2) variaram de 0,0909 a 0,5147 , sendo que a menor dissimilaridade foi observada entre os acessos 11 e $12(0,0909)$, e a maior dissimilaridade, entre os acessos 1 e $5(0,5147)$.

Oliveira et al. (2007), estudando a diversidade genética entre acessos de açaizeiro encontraram valores de dissimilaridade variando de 0,06 a 0,67 , demonstrando alta diversidade genética entre os acessos. Diante do exposto, é possível inferir que os resultados de dissimilaridade genética, neste trabalho, refletem uma variabilidade genética considerável entre os acessos de biribazeiro.

A alta dissimilaridade encontrada é justificada pelo fato de o biribazeiro ser uma frutífera ainda em processo de domesticação.

No dendrograma (Figura 1), pode-se observar a formação de seis grandes grupos, considerando a distância média de 0,60 entre grupos. O grupo G1 é composto por 3 acessos (11; 12 e 7); o grupo G2 com cinco acessos $(3 ; 13 ; 4 ; 16$ e 2$)$; o grupo G3 é formado por quatro acessos $(9 ; 10 ; 6$ e 8$)$; o grupo G4 possui dois acessos (14 e 15) e os grupos G5 e G6 são constituídos por apenas um indivíduo cada ( 1 e 5 , respectivamente).

A correlação cofenética evidenciou associação de $79 \%(\mathrm{CCC}=0,79)$ entre as distâncias obtidas na matriz de dissimilaridade (complemento de Jaccard) e a matriz cofenética. $O$ valor da correlação cofenética encontrado foi satisfatório, visto que valores superiores a 0,56 refletem boa concordância entre as matrizes (VAZ PATTO et al., 2004). De acordo com Cruz e Carneiro (2003), quanto maior o valor de CCC, menor será a distorção provocada ao agrupar os indivíduos, o que normalmente é obtido pelo método da ligação média (UPGMA).

Os resultados gerados neste trabalho estão de acordo com a literatura quanto à importância de marcadores moleculares, quando comparados a outros trabalhos, como o realizado por Junqueira et al. (2010) com pitaya, demonstrando a importância dos marcadores na análise de variabilidade de espécies pouco estudadas, como o Rollinia mucosa [Jacq.] Baill. 
TABELA 1- Marcadores ISSR utilizados na amplificação de acessos de biribá (Rollinia mucosa [Jacq.] Baill), com suas respectivas sequências), número total de bandas (NTB), número de bandas polimórficas e percentagem de polimorfismo. Alegre - ES, 2013.

\begin{tabular}{lcccc}
\hline Primers & Sequência (5'-3') & NTB & Polimórficas & \% de polimorfismo \\
\hline UBC 808 & AGA GAG AGA GAG AGA GC & 10 & 8 & 80 \\
UBC 810 & GAG AGA GAG AGA GAG AT & 7 & 6 & 85,7 \\
UBC 819 & GTG TGT GTG TGT GTG TA & 10 & 8 & 80 \\
UBC 827 & ACA CAC ACA CAC ACA CG & 5 & 5 & 100 \\
UBC 834 & AGA GAG AGA GAG AGA GYT & 13 & 12 & 92,3 \\
UBC 841 & GAG AGA GAG AGA GAG AYC & 13 & 12 & 92,3 \\
UBC 842 & GAG AGA GAG AGA GAG AYG & 11 & 7 & 63,6 \\
UBC 855 & ACA CAC ACA CAC ACA CYT & 10 & 7 & 70 \\
UBC 857 & ACA CAC ACA CAC ACA CYR & 6 & 5 & 83,3 \\
UBC 859 & TGT GTG TGT GTG TGT GRC & 8 & 8 & 100 \\
UBC 862 & AGC AGCAGCAGCAGCAGC & 6 & 0 & 0 \\
UBC 890 & VHV GTG TGT GTG TGT GT & 10 & 10 & 100 \\
UBC 899 & CAT GGT GTT GGT CAT TGT TCC A & 9 & 8 & 88,9 \\
\hline
\end{tabular}

TABELA 2- Matriz de dissimilaridade genética entre 16 acessos de biribá calculada com base no complemento do coeficiente de Jaccard, utilizando 118 fragmentos ISSR. Alegre - ES, 2013.

\begin{tabular}{|c|c|c|c|c|c|c|c|c|c|c|c|c|c|c|c|c|}
\hline \multirow{2}{*}{\multicolumn{2}{|c|}{2}} & 3 & 4 & 5 & 6 & 7 & 8 & 9 & 10 & 11 & 12 & 13 & 14 & 15 & 16 & \\
\hline & & 50.3171 & 10.3333 & 0.5147 & 0.3871 & 10.3333 & 0.2222 & 0.3708 & 0.4432 & 0.3726 & 0.3942 & 0.275 & 0.36 & 0.3699 & 0.3954 & 1 \\
\hline & 0 & 0.15 & 0.1646 & 0.3519 & 0.3563 & 30.2759 & 0.3521 & 0.381 & 0.2917 & 0.3044 & 0.2967 & 0.2963 & 0.2439 & 90.2333 & 0.2125 & 2 \\
\hline & & 0 & 0.1556 & 0.3636 & 0.2174 & 40.2766 & 0.2051 & 0.2609 & 0.2083 & 0.25 & 0.2292 & 0.1351 & 0.2 & 0.2222 & 0.2143 & 3 \\
\hline & & & 0 & 0.4342 & 0.368 & 0.2458 & 0.3333 & 0.3277 & 70.3273 & 0.2195 & 0.1984 & 0.2793 & 0.2963 & 30.321 & 0.1471 & 4 \\
\hline & & & & 0 & 0.375 & 0.4133 & 0.4043 & 0.2769 & 0.3571 & 0.4691 & 0.4634 & 0.4118 & 0.4151 & 10.3793 & 0.4203 & 5 \\
\hline & & & & & 0 & 0.36 & 0.1861 & 0.2091 & 0.1735 & 0.3561 & 0.3385 & 0.2909 & 0.3214 & 40.275 & 0.3684 & 6 \\
\hline & & & & & & 0 & 0.3918 & 0.374 & 0.3455 & 0.1818 & 0.2195 & 0.2946 & 0.2264 & 40.3372 & 0.3125 & 7 \\
\hline & & & & & & & 0 & 0.2169 & 0.2368 & 0.375 & 0.3884 & 0.3294 & 0.2162 & $2 \quad 0.3$ & 0.3412 & 8 \\
\hline & & & & & & & & 0 & 0.1667 & 0.3438 & 0.3516 & 0.2897 & 0.2353 & 30.3205 & 0.3839 & 9 \\
\hline & & & & & & & & & 0 & 0.3044 & 0.319 & 0.2857 & 0.1837 & 70.274 & 0.3232 & 10 \\
\hline & & & & & & & & & & 0 & 0.0909 & 0.1802 & 0.2983 & 30.2759 & 0.2759 & 11 \\
\hline & & & & & & & & & & & 0 & 0.1964 & 0.2807 & 70.3146 & 0.2609 & 12 \\
\hline & & & & & & & & & & & & 0 & 0.3111 & 10.32 & 0.2963 & 13 \\
\hline & & & & & & & & & & & & & 0 & 0.2093 & 0.3333 & 14 \\
\hline & & & & & & & & & & & & & & 0 & 0.2958 & 15 \\
\hline & & & & & & & & & & & & & & & 0 & 6 \\
\hline
\end{tabular}




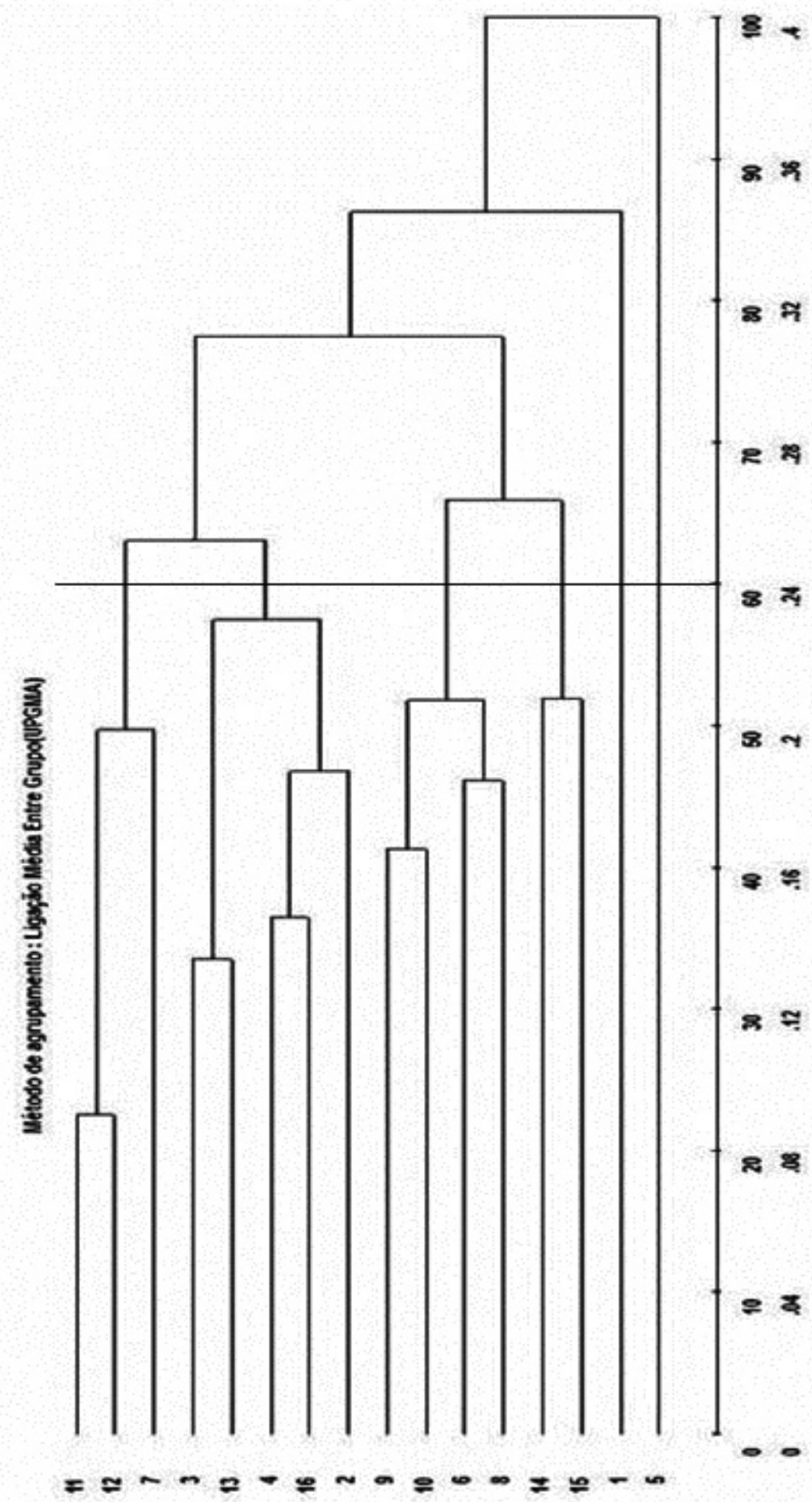

FIGURA 1-Dendrograma representativo da dissimilaridade genética entre os 16 acessos de biribá, obtido pelo método UPGMA (Unweighted Pair Group Method with Arithmetic Mean), utilizando o complemento aritmético do índice de Jaccard como medida de dissimilaridade, com base em marcadores ISSR (Inter Simple Sequence Repeats). Alegre - ES, 2013. 


\section{CONCLUSÃO}

1-Os marcadores ISSR foram eficientes na detecção de polimorfismos moleculares e, portanto, de variabilidade genética entre os acessos de biribazeiro.

2-Os acessos 5 e 1, respectivamente, foram os mais divergentes em relação aos demais.

\section{REFERÊNCIAS}

CAIXETA, E.T.; OLIVEIRA, A.C.B.; BRITO, G.G.; SAKIYAMA, N.S. Tipos de Marcadores Moleculares. In: BORÉM, A.; CAIXETA, E.T. (Org.). Marcadores moleculares. 2. ed. Viçosa: Editora Jard, 2009. v. 1. p.11-101.

CARVALHO, R.S.; PINTO, J.F.N.; REIS, E.F.; SANTOS, S.C.; DIAS, L.A.S. Variabilidade genética de cajuzinho-do-cerrado (anacardium humile st. hill.) por meio de marcadores RAPD, Revista Brasileira de Fruticultura, Jaboticabal, v.34, n.1, p.227-233, 2012.

CHEN, J. M.; GITURU, W.R.; WANG, Y.H.; WANG, Q.F. The extent of clonality and genetic diversity in the rare Caldesia grandis (Alismataceae): comparative results for RAPD and ISSR markers. Aquatic Botany, Amsterdam, v.84, n.4, p.301-307, 2006.

COSTA, J.P.C.; MÜLLER, C.H. Fruticultura tropical: o biribazeiro (Rollinia mucosa (Jacq.) Baill. Belém: EMBRAPA-CPATU, 1995. 35 p. (Documentos, 84).

CRUZ, C.D. Programa genes: Biometria. Viçosa: Editora UFV, 2006. 382p.

CRUZ, C.D.; CARNEIRO, P.C.S. Modelos biométricos aplicados ao melhoramento de plantas. Viçosa: UFV, 2003, v.2. 585p.

DANTAS, A.C.A.; NUNES, G.H.S.; ARAÚJO, S.I.; ALBUQUERQUE, L. B. Caracterização molecular de acessos de melão coletados no Nordeste brasileiro. Revista Brasileira de Fruticultura, Jaboticabal, v.34, n.1, p.183-189, 2012.
DINIZ, L.E.C.; SAKIYAMA, N.S.; LASHERMES, P.; CAIXETA, E.T.; OLIVEIRA, A.C.B.; MACIELZAMBOLIM, E.; LOUREIRO, M.E.; PEREIRA, A.A.; ZAMBOLIM, L. Analysisof AFLP markers associated to the Mex-1 resistance lócus in Icatu progênies. Crop Breeding and Applied Biotechnology, Viçosa, MG, v.5, p.387-393, 2005.

ESQUINCA, A.R.G.; MARTÍNEZ-VÁZQUEZ, M. Anxiolytic-like and sedative actions of Rollinia mucosa: Possible involvement of the GABA/ benzodiazepine receptor complex. Pharmaceutical Biology, Lisse, v.48, n.1, p.70-75, 2010.

ESTRADA-REYES, R.; LÓPEZ-RUBALCAVA, C.; ROCHA, L.; HEINZE, G, Lignans from leaves of Rollinia mucosa, Zeitschrift für Naturforschung, Tübingen, v.57, p.29-32, 2010.

FALEIRO, F.G. Marcadores genético-moleculares aplicados aos programas de conservação e uso de recursos genéticos. Planaltina: Embrapa Cerrados, 2007. $102 \mathrm{p}$

FERREIRA, M.G.R.; SANTOS, M.R.A.; SILVA, E.O.; GONÇALVES, E.P.; ALVES, E.U.; BRUNO, R.L.A. Emergência e crescimento inicial de plântulas de biribá (Rollinia mucosa (Jacq.) Baill) (Annonaceae) em diferentes substratos. Semina: Ciências Agrárias, Londrina, v.31, n.2, p.373-380, 2010.

JUNQUEIRA, K. P.; FALEIRO, F.G.; BELLON, G.; JUNQUEIRA, N. T. V.; FONSECA, K.G.F.; LIMA, C.A.; SANTOS, E.C. Variabilidade genética de acessos de pitaya com diferentes níveis de produção por meio de marcadores RAPD. Revista Brasileira de Fruticultura, Jaboticabal, v.32, n.3, p.840-846, 2010.

OLIVEIRA, M.S.P.; AMORIM, E.P.; SANTOS, J.B. dos; FERREIRA, D.F. Diversidade genética entre acessos de açaizeiro baseada em marcadores RAPD. Ciência e Agrotecnologia, Lavras, v.31, n. 6, p.1.645-1.653, 2007.

ROCHA, A.; SALOMÃO, L.C.C.; SALOMÃO, T.M.F.; CRUZ, C.D.; SIQUEIRA, D.L. Genetic Diversity of 'Ubá' Mango Tree Using ISSR Markers. Molecular Biotechnology, Totowa, v.50, n.2, p.108113, 2012. 
SANTANA, I.B.B.; OLIVEIRA, E.J.; SOARES FILHO, W.S.; RITZINGER, R.; AMORIM, E.P.; COSTA, M.A.P.C.; MOREIRA, R.F.C. Variabilidade genética entre acessos de Umbu-Cajazeira mediante análise de marcadores ISSR. Revista Brasileira de Fruticultura, Jaboticabal, v.33, n.3, p.868-876, 2011.

SANTOS, C.E.; ROBERTO, S.R.; MARTINS, A.B.G. Propagação do biribá (Rollinia mucosa) e sua utilização como porta-enxerto de pinha (Annona squamosa). Acta Scentiarum Agronomy, Maringá, v.27, n.3, p.433-436, 2005.
TEIXEIRA, P.C.; MACEDO, S.T. Calagem e fósforo para a formação de mudas de biribazeiro. Revista de Ciências Agrárias, Manaus, v.54, n.3, p.259266, 2011.

VAZ PATTO, M.C.; SATOVIC, Z.; PÊGO, S.; FEVEREIRO, P. Assessing the genetic diversity of Portuguese maize germoplasm using microsatellite markers. Euphytica, Wageningen, v.137, n.1, p.6372, 2004. 